\title{
The Future We Want
}

The title of this editorial is the same given to the main document to be discussed, two months from now, at the Earth Summit 2012, the so-called Rio+20, in allusion to the $20^{\text {th }}$ anniversary of the United Nations Conference on Environment and Development, also known as RIO-92.

The 1992 Summit, with its 27 principles, has been the most influential one because, beyond the environment itself, it placed human beings as the focus for the sustainable development, bringing, thus, for the discussion, issues such as hunger, diseases, disarmament, racial prejudice and genocide.

It was the most important document of RIO-92, Agenda 21, which, generally speaking, pointed out, for the signing nations, the protection of the environment and the promotion of the economic efficiency with social justice, defending the right to a healthy, just and productive life, in harmony with nature.

Several studies have been done in Brazil to check the effective results of RIO-92. In 1997, Cordani and co-workers recommended: "Definition of a national policy of prospection and biotechnology, together with the biodiversity conservation and preservation, as a way of aggregating the national biodiversity into the development process. There are two fundamental components for the sustainable development: high quality basic education and a solid system of science and technology. In addition, it is important to upgrade the current forestry policies, which emphasize the importance of forests as a wood producer, to a level in which the environmental services of the forests are considered fundamental for the implementation of the Conventions of Climate and Biodiversity". ${ }^{1}$
Ten years after RIO-92, in Johannesburg, South Africa, we had Rio+10 on Sustainable Development and Environment and Development. At that Summit, it was reinforced the necessity of reducing mankind's action on the environment, of eradicating poverty, of achieving the sustainable development with protection to the biodiversity, of providing access to drinking water, to renewable energy, to food security, to sanitation, to housing and health, with emphasis on both the neglected and the chronic transmitted diseases.

There can be no doubt that the Principles of RIO92 should continue to lead the world and serve as a basis for cooperation and the implementation of the agreed commitments. Thus, it is not surprising that the RIO+20 document, under discussion, reaffirm several issues from RIO-92, such as the sustainable development under the economic, social and environmental aspects, the eradication of hunger and all forms of poverty and the struggle for more just and inclusive societies, with economic stability and social progress.

The distance between speech and actions is very large. In 2009, during COP- $15,{ }^{2}$ Brazil voluntarily took on goals for reducing the greenhouse effect gases by reducing deforestation or, at least, reaching a balance: cut down forests less recovered forests equaling zero. In spite of the fact that the deforestation rate has decreased, almost nothing has improved concerning the recovery of degraded areas. Our forestry code is still being debated. We are still discussing whether we should reduce our native forests for the agribusiness and whether we should recover the degraded areas. So, apparently, concerning that, we still have a lot to learn. 
Chemistry can not simply keep talking about a Green Chemistry; it should contribute for a green and sustainable economy. We should start acting and developing new technologies that respect the environment and are socially inclusive. Our natural resources should be harnessed and explored rationally in order to generate wealth for the Brazilian people. For that, we need more research groups dedicated to the area and more resources from the funding agencies to face issues such as recyclable materials from renewable sources, the development of new and more effective reactions providing more atomic economy and less environmentally aggressive waste, new alternative sources of energy and of biofuels. But, in what concerns federal resources for scientific and technological researches, we are moving backwards.

Are governments and corporations prepared for the debate with society? Would our society replace the excessive profit and consumerism by a more adequate attitude towards the commitments intended by the
Rio+20 Summit? Would it be a daydream to imagine the following situation: undersigning, all Heads of States and Governments, meeting in Rio de Janeiro, Brazil, on June 20 - 22, 2012, decide to take on the unconditional commitment to work together for a prosperous and egalitarian future, with no hunger or poverty, with ethnic and religious tolerance, safe and with a sustainable development to preserve life and the planet? A good start would be the developed nations sharing the scientific information on the climate with all the others.

Vitor F. Ferreira

Universidade Federal Fluminense

\section{References}

1. Cordani, U. G.; Marcovitch, J.; Salati, E. Estud. av. 1997, 11, Jan./Abr.

2. $15^{\text {th }}$ Conference of the Parties to the UN Framework Convention on Climate Change (COP15) held in Copenhagen, Denmark, from Dec. 7 to 18, 2009: http://www.denmark.dk/en/menu/ Climate-Energy/COP15-Copenhagen-2009/cop15.htm 